\title{
РАЗВИТИЕ ИНТЕРНЕТ- МАРКЕТИНГА В УСЛОВИЯХ ПАНДЕМИИ НА ПРИМЕРЕ DIY-ГИПЕРМАРКЕТА ОБИ
}

\author{
(c) 2021 Сапегина Карина Зиад \\ аспирант Высшей школы сервиса и торговли \\ Института промышленного менеджмента, экономики и торговли \\ Санкт-Петербургский политехнический университет Петра Великого, Россия, Санкт-Петербург \\ E-mail: sapegina.k@edu.spbstu.ru
}

Статья посвящена анализу развития интернет- маркетинга в условиях пандемии на примере федеральной торговой сети DIY формата ОБИ. Представлена аналитика по динамике развития продаж е-сommerce на региональном рынке г. Санкт-Петербурга, а также по России в целом. В статье рассмотрены причины, которые спровоцировали резкое смещение взгляда торговых сетей на онлайн- торговлю. Также проанализированы современные маркетинговые инструменты, используемые сетью ОБИ для развития онлайн- магазина и мОБИльного приложения.

Ключевые слова: торговые сети, онлайн- маркетинг, digital-среда, етаil- рассылки, социальные сети

Торговым сетям, стремящимся обеспечить своё выживание на потребительском рынке, необходимо быть очень гибкими: оперативно реагировать на любые изменения окружающей среды и колебания экономики.

Эпидемия COVID-19 спровоцировала изменение в структуре рынка потребления, потребительских запросов, поэтому торговые сети, для поддержания своей конкурентоспособности, вынуждено пришли к оптимизации всех бизнеспроцессов и погружению в онлайн- торговлю.

Количество времени, проводимое в digitalсреде, значительно увеличилось в период самоизоляции: 84\% населения России впервые попробовали новый онлайн-сервис или услугу в режиме пандемии. Тренд на цифровизацию бизнеса наблюдался и ранее, режим изоляции его лишь ускорил. Так, в 2020 году доля продаж через Интернет по Российской Федерации увеличилась на $1,9 \%$ по сравнению с предыдущим 2019 годом, и на 2,2\% по сравнению с 2018 годом (рисунок 1).

На региональном рынке г. Санкт-Петербурга в 2020 году прирост интернет- торговли составил $2,8 \%$ по сравнению с 2019 годом и на 3,1\% по отношению к 2018 году [1].

Увеличение количества интернет-пользователей, снижение издержек на привлечение клиентов в цифровой среде ставят вопрос о необходимости трансформации маркетинговых бюджетов в онлайн-продвижение, в котором главное внимание должно быть уделено пользователю. Чтобы обеспечить максимальную прибыль от внедрения онлайн-сервисов, необходимо тщательно изучить потребителя, направить внимание на развитие социальной коммерции

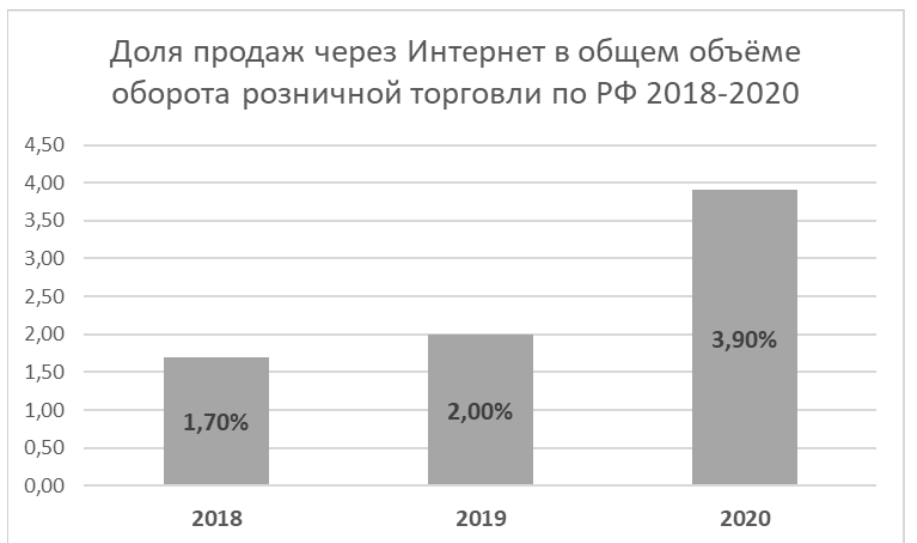

Puc. 1. Доля продаж через Интернет в общем объёме оборота розничной торговли по РФ 2018-2020 г.г. [1] 
и персонализации маркетинговых инструментов.

Рассмотрим развитие онлайн- маркетинга на примере сети ОБИ- одного из лидеров в сегменте DIY-гипермаркетов на российском потребительском рынке.

Статистика онлайн-гипермаркета ОБИ такая: более 4 миллионов посещений сайта в месяц, каждый пользователь посещает не менее 6 страниц за одно посещение, в среднем на сайте покупатель проводит более 5 минут.

Аудиторию онлайн-гипермаркета ОБИ в большей степени составляют женщины (52\%), 48\%- мужчины в возрастной категории 24-44 лет (рисунок 2,3).

Сеть ОБИ используют различные современные маркетинговые каналы: мОБИльное приложение, email- рассылки и социальные сети.

МОБИльное приложение является дополнительным преимуществом сети. Этот канал наиболее современный и активно развивающийся. Текущая версия мОБИльного приложения ОБИ демонстрирует высокий уровень конверсии, стабильный рост дохода и рост лояльности аудитории. Основной доход приложению приносят лояльные покупатели, выбравшие этот инструмент для покупок в качестве основного на период ремонта, обустройства дома или дачного участка.

ОБИ осуществляет брендированные рассыл- ки и анонсируют акции и новинки ассортимента. Клиентская база составляет около 1 млн. покупателей. У данного инструмента есть ряд преимуществ:

- Быстрый отклик

- Высокая конверсия

- Сегментация и персонализация

- Рост лояльности целевой аудитории

- Получение обратной связи от пользователей

Дополнительным источником привлечения покупателей являются социальные сети. Социальные сети ОБИ имеют более 300000 подписчиков. Посредством социальных сетей происходит размещение брендированного контента, анонс акций и конкурсов.

Помимо внутренних каналов поддержки онлайн-маркетинга, ОБИ пользуется и внешними: инструменты онлайн-маркетинга в покупательской воронке, использование каналов коммуникаций, контекстная реклама, размещение товаров в каталогах ЯндексМаркет, партнерские сети, ретаргетинг, медийная реклама.

Комбинирование и развитие каналов интернет-рекламы дают ОБИ возможность взаимодействовать и привлекать покупателей на каждом этапе их потребительского пути. ОБИ использует все каналы коммуникаций, постоянно повышая их эффективность как в Performanceстратегии (KPI-Cost of Sales), так и в Медийной

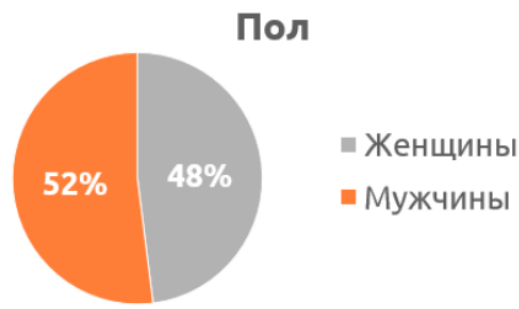

Puc. 2. Разделение покупателей онлайн- гипермаркета ОБИ по половому признаку [4]

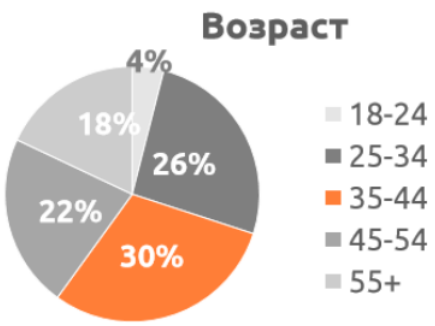

Puc. 3. Разделение покупателей онлайн- гипермаркета ОБИ по возрастному признаку [4] 
рекламе (рисунок 4).

Контекстная реклама- тип интернетрекламы, при котором рекламное объявление показывается в соответствии с содержанием, выбранной аудиторией, местом, временем или иным контекстом интернет-страниц.

ОБИ осуществляет комплексное продвижение бренда по всей покупательской воронке, оказывая качественный сервис на всем этапе взаимодействия покупателя с ОБИ (рисунок 5).

«Яндекс. Маркет»- сервис для выбора и покупки товаров. Пользователям сервиса доступны более 230 млн. предложений от 25 тыс. российских и зарубежных интернет-магазинов. Сервис позволяет пользователям сравнивать товары по параметрам и ценам, изучать отзывы и обзоры, а также задавать вопросы другим посетителям сайта, магазинам и производителям.

ОБИ представлен на всех крупнейших площадках по сравнению цен в карточных и некарточных категориях (рисунок 6).

ОБИ транслирует все акции и промопредложения крупнейшим партнерским сетям, которые привлекают заказы за счет качественного взаимодействия с отобранными вебмастерами. В 2020 году ОБИ запустили собственную партнерскую сеть, которая позволила сократить издержки на привлечение заказов на obi.ru. Это сделало данный канал рекламы самым эффективным с точки зрения дохода на инвестиции.

На рисунке 7 представлен пример взаимодействия с брендом/товарами посредством партнерской сети.

Динамический ретаргетинг - это персонализированный автоматический механизм, позволяющий показывать пользователю баннеры с теми товарами/ услугами, которые он совсем недавно просматривал на сайте рекламодателя, но при этом не совершил активное действие (заказ, регистрация, корзина и т.п.).

Пример действия динамического ретаргетинга на сайте ОБИ представлен на рисунке 8.

Медийная реклама - это размещение текстовых и графических рекламных материалов (баннеров, видеороликов) на новостных порталах, отраслевых и тематических сайтах, виде-

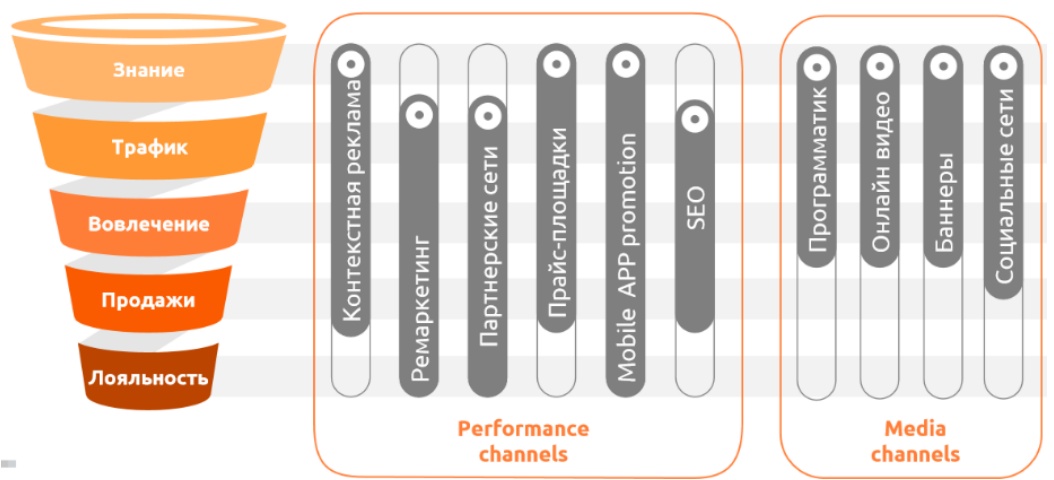

Puc. 4. Инструменты онлайн- маркетинга в покупательской воронке

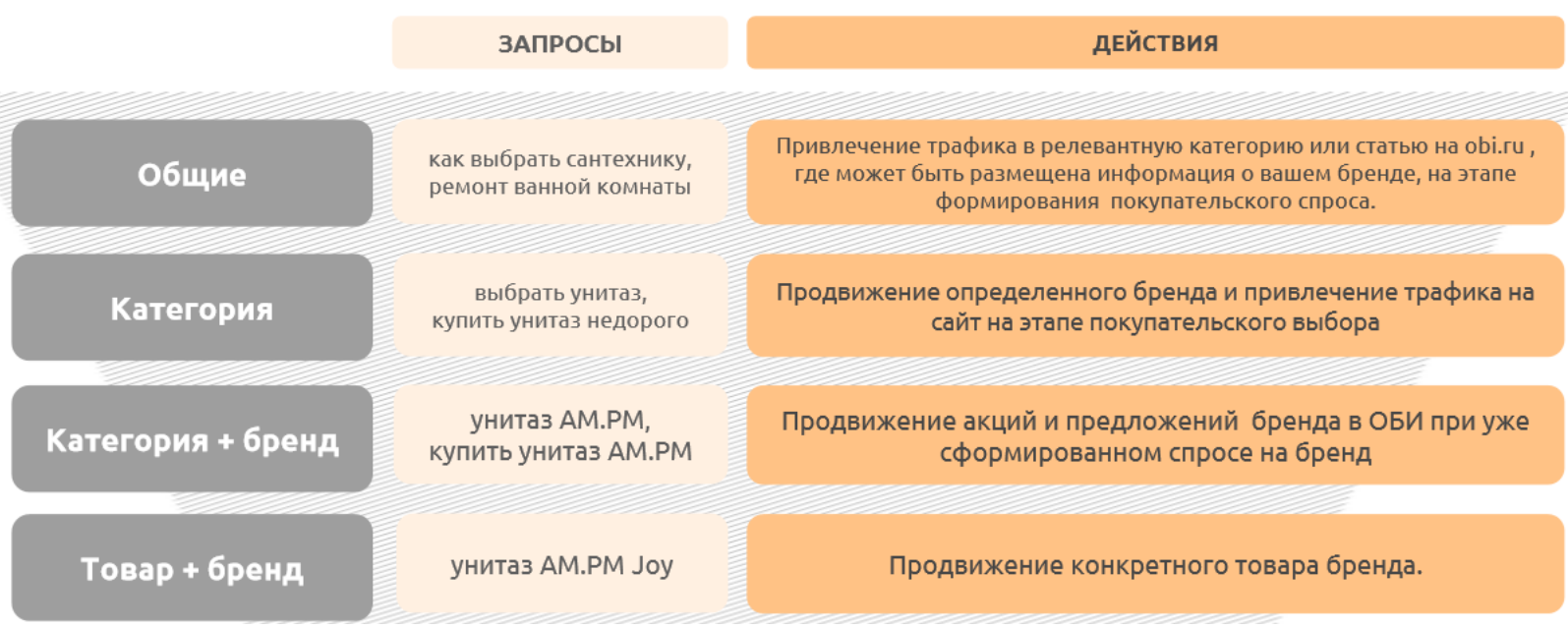

Puc. 5. Подход к категориям запросов в рамках контекстной рекламы ОБИ 

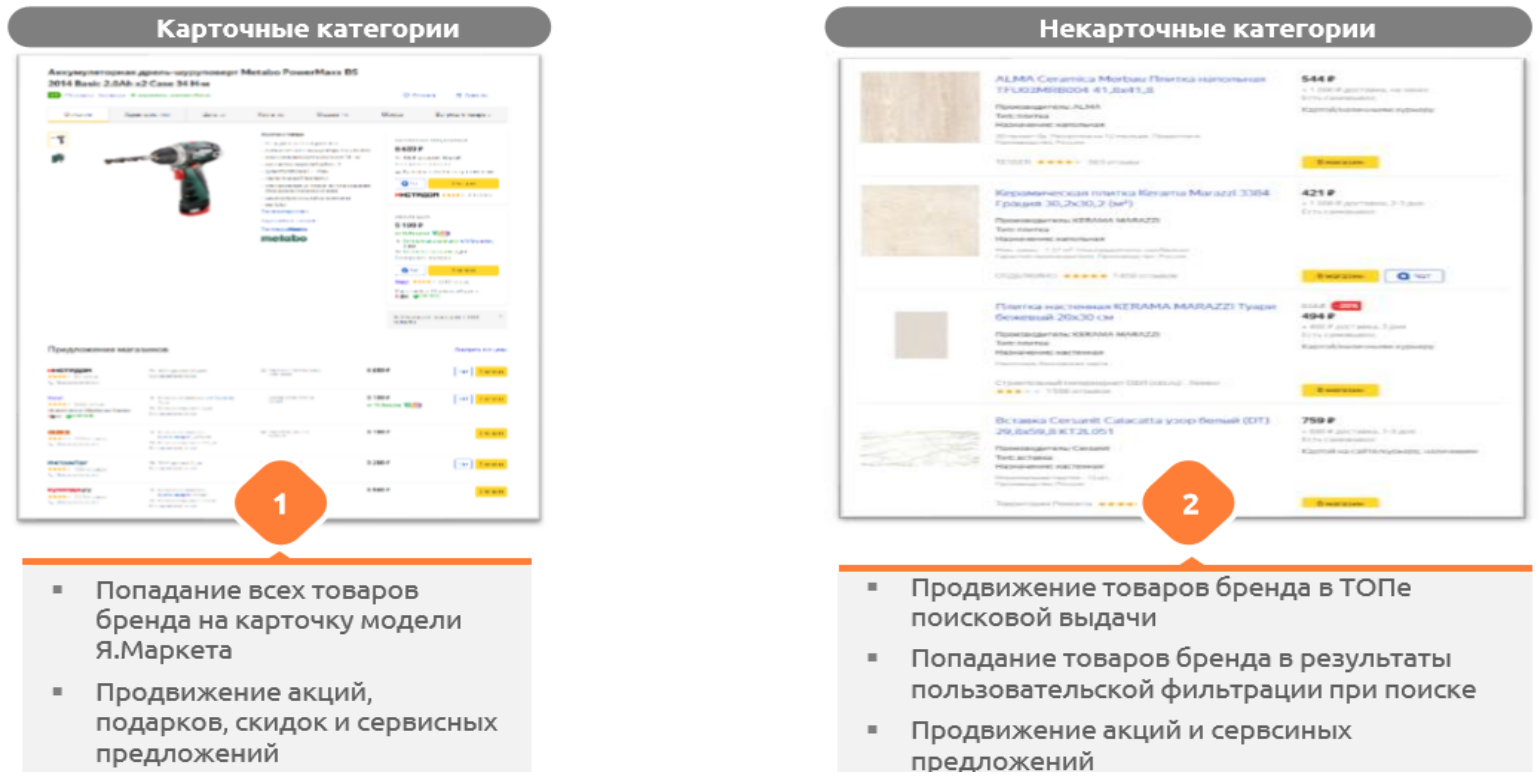

Puc. 6. Размещение товаров ОБИ в каталогах Яндекс.Маркет [3]

ОБИ анонсирует акцию: «Повышенный кэшбэк за покупку товаров бренда X»

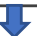

Партнерская сеть транслирует условия акции Вебмастерам, которые запускают рекламную поддержку на ЦА

Покупатели получают дополнительную мотивацию и приобретают товар бренда Х в ОБИ

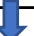

Покупатель получает повышенный кэшбэк или бонусы за покупку

бренда X

Puc. 7. Пример взаимодействия бренда/товара посредством партнерской сети
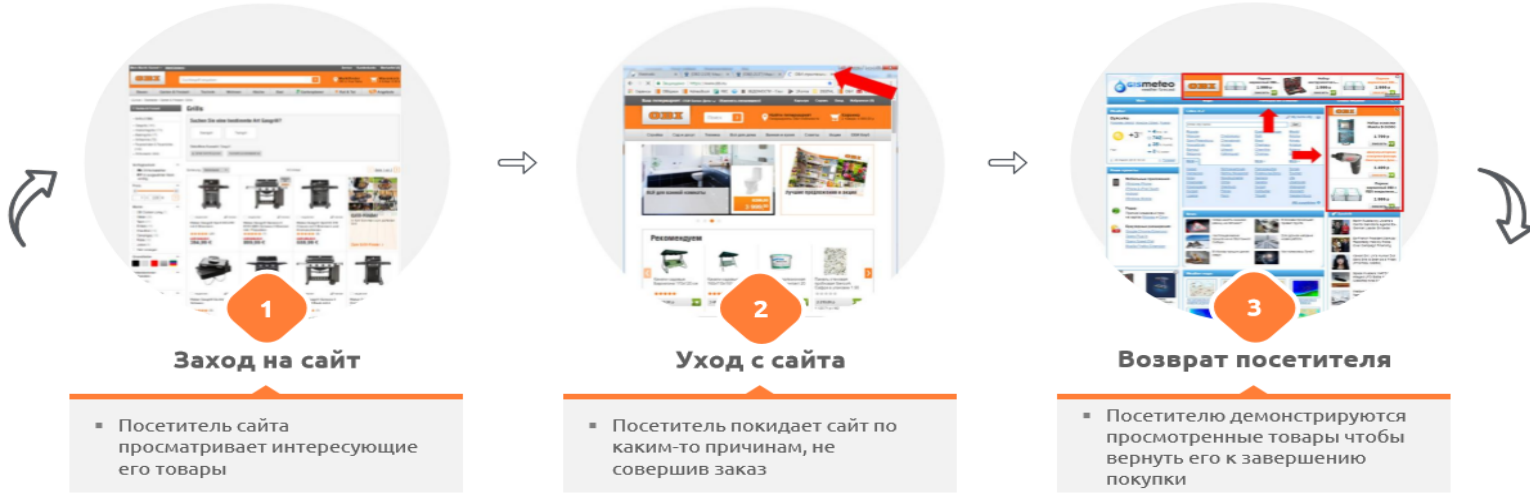

Puc. 8. Пример действия динамического ретаргетинга на сайте ОБИ [2] 
охостингах, в тизерных и RTB-сетях, а также во многих других местах размещения контента.

ОБИ использует программатик-закупки рекламы - автоматизированная реклама, которая позволяет показывать анимированные баннеры заранее выбранным сегментам пользователей. Основанная на работе с большими данными, программатик-реклама автоматизировано демонстрируется наиболее релевантной аудитории в зависимости от интересов и совершенных покупок и прочих настроек в таргетинге (всего около 400 сегментов).

Несмотря на общее падение продаж в период пандемии 2020 года из-за временных ограничений в виде закрытия оффлайн магазинов, доля продаж по средствам интернет- магазина и мОБИльного приложения увеличилась на 33\% в сравнении с аналогичным периодом 2019 года. Использование рассмотренных маркетинговых инструментов помогло удержать клиентов компании, а также развить направление интернетторговли [4].
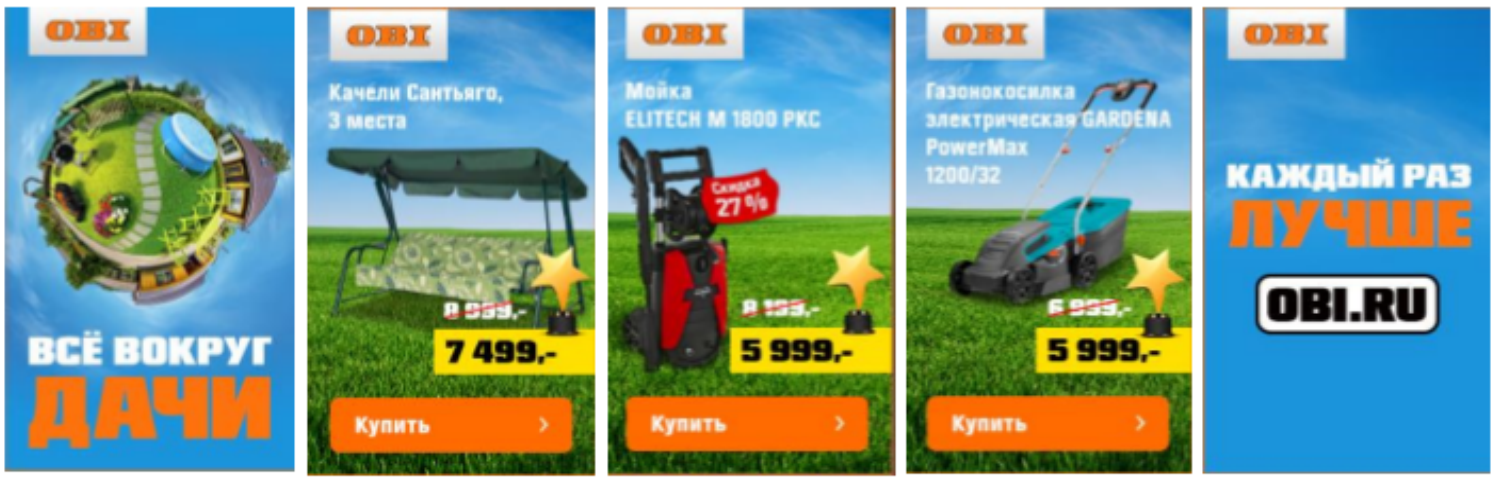

Рис. 9. Пример раскадровки анимированного баннера на сайте ОБИ [2]

\section{Библиографический список}

1. Федеральная служба государственной статистики / [Электронный ресурс]. - Режим доступа: https://rosstat. gov.ru/

2. Официальный сайт ОБИ / [Электронный ресурс]. - Режим доступа: https://www.obi.ru/

3. Яндекс.маркет / [Электронный ресурс]. - Режим доступа: https://market.yandex.ru/

4. Потребительская панель Romir ОБИ / [Электронный ресурс]. - Режим доступа: https://romir.ru/consumerscan-panel

5. Красюк И.А. Теоретико-методологические основы маркетинговой концепции организации розничной торговли в регионах, моногр. СПб.: Изд-во Политехн. ун-та, 2018. 252 с.

6. Данилов Н.А. Маркетинговый потенциал региона. Предпосылки формирования маркетингового потенциала // Вопросы управления. 2018. № 3(33). С. 66-69.

7. Горелова Т.П. Маркетинговый потенциал региона // Вестник академии. 2016. № 11. С. 21-25.

8. Ashworth, G.J., Voogd H. Marketing the city: concepts, process and Dutch applications // Town Planning Review. 1988. Vol 59 (1). P. 65-79.

9. Meer J. van der. The Role of City Marketing in Urban Management. Rotterdam: Euricur, Erasmus University, 1992. $432 \mathrm{p}$.

10. Котлер Ф., Асплунд К., Рейн И., Хайдер Д. Маркетинг мест. Привлечение инвестиций, предприятий, жителей и туристов в города, коммуны, регионы и страны Европы. СПб: Стокгольм. шк. экономики в СанктПетербурге, 2005. 376 с.

11. Лавров А.М., Сурнин В.С. Реформирование экономики: региональные аспекты Региональный маркетинг и тенденции его развития. Кемерово: Кузбассвузиздат, 1994. 106 с.

12. Канюка Ю.Г. Совершенствование подходов к формированию, развитию и использованию маркетингового потенциала компании на новых рынках: автореф. дисс. ... канд. экон. наук: 08.00.05. Санкт-Петербург, 2017, ФГБОУ ВО Санкт-Петербургский государственный экономический университет. 20 с. 
13. Крымов С.М., Магомедов М.Г., Месхи Б.Ч., Писарева Е.В., Плотников А.В., Симонян Т.В., Кондратьева М.Н., Бутова Т.Г.Гапоненко Татьяна Валерьевна Горбачева И.Е., Гуськов А.И., Жуков П.В., Изотов М.А., Казакова Л. В., Красюк И. А., Мартынова Н.В //Актуальные проблемы организации производства, маркетинга и менеджмента: коллективная монография.2012

14. Красюк (Дудакова) И.А., Крымов С. М. Научно-практические и методические основы организации розничной торговой сети в регионах//Актуальные проблемы организации производства, экономики и маркетинга//Актуальные проблемы организации производства, экономики и маркетинга.2011. 140 с., с. $72-88$ 